\title{
HERNIA DE LITTRÉ ESTRANGULADA A PROPÓSITO DE UN CASO
}

\author{
JUAN PABLO LUENGAS ${ }^{1}$, PAOLA ANDREA SACRISTÁN R. ${ }^{2}$; \\ KATHERINE SÁENZ REY'; ISABELLA SANABRIA ESGUERRA ${ }^{2}$ \\ ${ }^{1}$ Cirujano Pediatra Instituto Nacional de Cancerología \\ ${ }^{2}$ MD. Egresada Universidad Militar Nueva Granada \\ Correspondencia: Paola Andrea Sacristán Rodríguez. pao_jmc@hotmail.com
}

Recibido: 28 Agosto 2015 Aceptado: 11 Noviembre 2015

\section{RESUMEN}

La Hernia de Littré es una patología rara de incidencia desconocida. Su sospecha clínica es infrecuente dada la inespecificidad de la sintomatología con la que debuta, por lo que su diagnóstico suele realizarse intraoperatoriamente. Se presenta el caso de un paciente con cuadro clínico de dolor abdominal agudo, masa no reductible y dolorosa en región inguinoescrotal derecha, a quien desde el ingreso se sospecha que presenta una hernia estrangulada. Tras una intervención quirúrgica de urgencia se realiza hallazgo intraoperatorio de hernia de Littré perforada. El paciente fue dado de alta en su sexto día postoperatorio en buenas condiciones generales.

Palabras Clave: Hernia, Littré, divertículo de Meckel, Cirugía. 


\title{
ESTRANGULATED LITTRE HERNIA.
}

\section{A CASE REPORT}

\begin{abstract}
Littre's hernia is a disease of unknown incidence, it's clinical suspicion is infrequent given the lack of specificity of the symptoms, therefore it's diagnosis is made intrasurgicaly. We report the case of a patient that consulted due to acute abdominal pain, irreducible and painful mass in the right inguinal region, who since admission was suspected of having a strangulated hernia. After an emergency surgery the intraoperative finding of perforated Littre hernia was performed. The patient was discharged on the sixth postoperative day in good general conditions.
\end{abstract}

Keywords: Hernia, Littre, Meckel's diverticulum, Surgery.

\section{ESTRANGULADO LITTRE HERNIA. UM RELATO DE CASO}

\begin{abstract}
RESUMO
A hérnia de Littre é uma doença de incidência desconhecida, é suspeita clínica é infreqüente, dada a falta de especificidade dos sintomas, portanto, seu diagnóstico é feito intra-cirúrgico. Relatamos o caso de um paciente que consultou devido a dor abdominal aguda, massa irredutivel e dolorosa na região inguinal direita, que desde a admissão foi suspeita de ter uma hérnia estrangulada. Após uma cirurgia de emergência foi realizado o achado intraoperatório de hérnia de Littre perfurada. A paciente recebeu alta hospitalar no sexto dia pós-operatório em boas condições gerais.
\end{abstract}

Palavras-chave: Hérnia, Littre, divertículo de Meckel, Cirugía. 


\section{Introducción}

Etimológicamente la palabra hernia puede ser tomada del vocablo griego "epivos" (brote) e "hira" (intestino) o del latín del cual se traduce como rotura. Se entiende como hernia, la protrusión de un elemento intra-abdominal por un orificio anatómicamente constituido. Esta definición menciona el término "protrusión" reemplazando al de "pasaje" ya que algunos elementos de la hernia sólo se insinúan en el orificio anatómico sin atravesarlo por completo (antes conocido como "punta de hernia"). De manera general, los elementos que constituyen una hernia pueden ser: epiplón, grasa preperitoneal o un órgano diferente al intestino, siendo este último el más frecuente en presentación. Según el contenido del saco herniario se han establecido algunos epónimos que facilitan el reconocimiento y clasificación de esta patología abdominal (1).

La hernia de Littré, por ejemplo, se define como la protrusión del divertículo de Meckel a través de un orificio en la pared abdominal. Éste es considerado un resto primitivo del conducto onfalomesentérico, el cual en el embrión comunica al intestino medio con el saco vitelino desde la primera hasta la quinta semana de gestación. Además, cumple la función de proveer la nutrición del feto en formación hasta que se establezca la placenta $(2,3)$.

Normalmente, este conducto involuciona de la quinta a la séptima semana, convirtiéndose en un haz delgado de tejido fibroso que desaparece finalmente a la décima semana de gestación. Si existe algún tipo de falla completa o parcial en esta involución, resultan varias estructuras residuales como lo son: el seno umbilical, la fístula onfalomesentérica, el pólipo umbilical, una brida alantoidea, el quiste del conducto onfalomesentérico y en mayor frecuencia el divertículo de Meckel, originado cuando el extremo del íleon se encuentra permeable mientras su extremo umbilical está atrofiado (2-4).

Aproximadamente entre un 6 y $17 \%$ de los divertículos de Meckel pueden presentar adherencias inflamatorias y modularidad tanto en el divertículo como en el saco herniario, produciendo una hernia crónicamente incarcelada. Este divertículo tiene una incidencia aproximada de $2 \%$ a nivel mundial, siendo sólo un 4 a $6 \%$ los que producirán sintomatología (más frecuentemente durante la infancia). Por su parte, la hernia de Littré tiene una incidencia y prevalencia hasta el momento desconocida y su hallazgo en la mayoría son hallazgos intraoperatorios quirúrgicos incidentales. Se han reportado muy pocos casos en la literatura, por lo que se considera pertinente documentar este caso (Ver más adelante) (1,3,5-9).

\section{Reporte de caso}

Se presenta el caso de un paciente de sexo masculino de 47 años de edad, sin patología médica de base, quien acude al servicio de urgencias, por cuadro clínico de cuatro horas de evolución consistente en la presencia de una masa en región inguinoescrotal derecha, no reductible y dolorosa, con intensidad 9/10 en la escala subjetiva del dolor, sin otra sintomatología asociada.

Al examen físico se encuentra un abdomen plano, simétrico, ruidos hidroaéreos disminuidos, poco depresible, doloroso a la palpación profunda, con moderada defensa muscular. En región inguinal derecha se ve y se palpa una masa de aproximadamente siete centímetros de diámetro, no reductible, dolorosa y que incrementa su tamaño con maniobras de Valsalva. Se toman paraclínicos donde se encuentra un hemograma dentro de límites normales y función renal conservada.

Finalmente, se deja como diagnóstico de ingreso una hernia inguinal derecha estrangulada. Se interviene quirúrgicamente de urgencia, encontrando hernia inguinal con divertículo de Meckel deslizado (hernia de Littré), estrangulado en saco herniario y al parecer perforado, con isquemia de íleon a $2.5 \mathrm{~cm}$ distal y proximal del divertículo.

Se realiza una incisión transversa de la piel a unos 3.5 $\mathrm{cm}$ por encima de la espina ilíaca anterosuperior y lateral a $3 \mathrm{~cm}$ del ombligo, disección por planos hasta identificar saco herniario que protruía a través del orificio inguinal profundo, resección del segmento del íleon que contenía el divertículo de Meckel perforado con posterior anastomosis termino-terminal y corrección de la hernia con técnica de Lichtenstein. En el postoperatorio, el paciente tiene una evolución tórpida con íleo paralítico que se resuelve al tercer día, dando egreso al sexto día de hospitalización en buenas condiciones generales.

El estudio anatomopatológico del divertículo reveló a nivel macroscópico una formación sacular de $4.5 \mathrm{~cm}$ de diámetro, sin contenido en suinterior, conadelgazamiento de la pared, resto de la mucosa beige homogénea, pared de 0,4 cm de espesor. Microscópicamente, segmento de tubo digestivo con infarto transmural y denso infiltrado 
agudo inespecífico. En áreas mejor preservadas se observan los componentes de la pared intestinal con mucosa de tipo intestino delgado.

\section{Discusión}

La primera descripción del divertículo de Meckel fue realizada por Fabricius Hildanus en 1598, aunque su descripción del origen embriológico y la relación entre el divertículo y el conducto onfalomesentérico no se realizó sino hasta el año 1809 por Johann Friedrich Meckel, donde finalmente recibe el nombre de divertículo de Meckel. Posteriormente, en 1700 el cirujano francés Alexis de Littré, reportó este divertículo ileal y lo atribuyó a la tracción que se realizaba sobre el íleon; publicando los primeros casos en la revista "Mémoires de l'Àcadémie Royale des Sciences"; adjudicándole así el nombre de hernia de Littré. Finalmente la diferenciación entre la hernia de Littré y la hernia de Richter (pinzamiento lateral del intestino delgado, pero que no contiene un divertículo de Meckel) no se logró sino hasta el año 1897 por Sir Frederic Treves $(1-3,6,10)$.
Como se explicó en el inicio de este artículo, la hernia de Littré se define como la protrusión del divertículo de Meckel a través de un orificio en la pared abdominal. Por esta razón se hace necesaria una pequeña revisión de las principales características de este divertículo, haciendo énfasis que éste por si solo representa una patología aislada que puede presentarse como otro diagnóstico diferencial de un cuadro de abdomen agudo $(2,5,6,8)$.

El divertículo de Meckel histológicamente contiene todas las capas de la pared intestinal por lo que se considera un divertículo verdadero. Se ubica generalmente en el borde antimesentérico del íleon a una distancia de la válvula ileocecal que varía de 10 a $150 \mathrm{~cm}$, con una longitud de 4 a $10 \mathrm{~cm}$ y un diámetro de $2 \mathrm{~cm}$. En un $30 \%$ es posible encontrar mucosa ectópica, siendo la gástrica la más común. Se han descrito casos en la literatura que describen mucosa duodenal, colónica $e$ islotes pancreáticos. Se ha descrito en varias ocasiones como el divertículo que cumple la regla del 2 (Ver tabla 1) $(1,2,4-8)$.

Tabla 1. Regla del "2" para el divertículo de Meckel

Se observa en el $2 \%$ de la población

Relación Hombre: Mujer 2:1

Se encuentra a 2 pies $(60 \mathrm{~cm})$ de la válvula ileocecal

Tiene 2 pulgadas de largo $(5 \mathrm{~cm})$

Tiene $2 \mathrm{~cm}$ de diámetro

Se vuelve en su mayoría sintomático antes de los 2 años de edad

Contiene comúnmente 2 tipos de tejidos heterotópicos sobre todo gástrico y pancreático

La mayoría de los pacientes portadores del divertículo de Meckel son asintomáticos y se diagnostican incidentalmente durante alguna evaluación radiológica del intestino delgado, en procedimientos quirúrgicos realizados por patologías no relacionadas o durante la realización de la necropsia. Estos portadores presentan un riesgo de por vida de 4 a $6 \%$ de desarrollar complicaciones clínicas, aunque la presentación de éstas se da más frecuentemente en niños (ver tabla 2). El 60\% de los divertículos se vuelven sintomáticos en la primera década de la vida, con un segundo pico en mayores de 70 años $(1,3,9,11,12)$.

Cabe destacar dentro de estas complicaciones que la hemorragia intestinal es el hallazgo más prevalente en la edad pediátrica (promedio 2 años) y se manifiesta como un episodio indoloro, sin melena, asociado generalmente a enfermedad ulceropéptica de la mucosa gástrica heterotópica del divertículo $(8,13-15)$.
Tabla 2. Complicaciones del divertículo de Meckel

1. Obstrucción intestinal

2. Sangrado

3. Inflamación

4. Perforación

5. Vólvulo

En general, el dolor abdominal, las náuseas, los vómitos, el sangrado rectal y la distensión del abdomen son los síntomas más comunes. La frecuencia de presentación de los síntomas varía con la edad, siendo más común encontrar en el recién nacido la obstrucción intestinal (bajo la forma de vólvulo o de invaginación), por su parte, en infantes y niños pequeños se evidencia el sangrado intestinal bajo no doloroso, y finalmente en los niños más grandes y en los adultos, la presentación común es la inflamación que simula clínicamente un cuadro 
de apendicitis. Los síntomas oclusivos también son frecuentes en adultos $(1,5,16,17)$.

En pacientes menores de 18 años, la hemorragia digestiva se presenta en $55 \%$ de los casos y en $90 \%$ de ellos se debe a la presencia de mucosa gástrica heterotópica. En ausencia de hemorragia, el diagnóstico de divertículo de Meckel es difícil en adultos. Menos del $10 \%$ de todos los divertículos de Meckel son sintomáticos. Por lo tanto se debe considerar en cualquier paciente con molestias abdominales inexplicables, náuseas y vómitos o sangrado intestinal $(3,6,11)$.

La obstrucción intestinal, por su parte, ocurre en el $40 \%$ de los divertículos de Meckel sintomáticos, y es causada por la captura de un asa intestinal por una banda mesodiverticular, vólvulos del divertículo alrededor de una banda mesodiverticular, intususcepción, extensión a un saco herniario (hernia de Littré) y litiasis del divertículo $(15,18,19)$.

Como herramientas diagnósticas, el ultrasonido ecográfico presenta limitantes en el diagnóstico del divertículo de Meckel sin presencia de inflamación, donde no se distingue de otras asas intestinales. En los casos de inflamación, según la afección de la pared, se puede evidenciar una estructura tubular llena de líquido, con una pared fina (si hay poca inflamación parietal).
Si por el contrario hay compromiso extenso de la pared, el divertículo puede aparecer como una masa de partes blandas adyacente al asa intestinal, con paredes engrosadas. La enteroclisis o el estudio con doble medio de contraste se consideran mejores alternativas de estudio. Sin embargo, el examen de medicina nuclear con Tecnesio 99 permite detectar con buena sensibilidad el sitio del sangrado o la mucosa ectópica del divertículo. Esta sensibilidad en población pediátrica se acerca al $90 \%$ pero decrece de manera importante en adultos alcanzando un $46 \%(15,16,17)$.

Finalmente, la diverticulitis de Meckel puede simular distintos cuadros clínicos, entre ellos una enfermedad úlceropéptica, gastroenteritis, cólico biliar, diverticulitis colónica y apendicitis aguda (en mayor frecuencia) (15).

En contraposición al divertículo de Meckel, es poca la información reportada en la literatura sobre las características específicas y reportes de caso sobre la Hernia de Litré (ver tabla 3). La localización de esta hernia es en su mayoría inguinal (50\%), seguida por la umbilical (20\%) y femoral (20\%). El $10 \%$ restante corresponde a localizaciones poco frecuentes. El diagnóstico preoperatorio de una hernia de Littré es raro y difícil siendo la mayoría diagnosticados de manera intraoperatoria. La sospecha inicia con una anamnesis y examen físico completo $(1-3,6,11,15,19)$.

Tabla 3. Casos reportados en la literatura sobre la Hernia de Littré

\begin{tabular}{|c|c|c|c|c|}
\hline Año & Edad & Enfermedad Asociada & Técnica Quirúrgica & Autor (Ref) \\
\hline 2004 & 42 años & Hernia inguinal & $\begin{array}{c}\text { Conservador- reducción a cavidad } \\
\text { peritoneal }\end{array}$ & Valente y cols (4). \\
\hline 2005 & 4 años & $\begin{array}{c}\text { Masa inguinal +criptorquidia } \\
\text { ipsilateral }\end{array}$ & $\begin{array}{c}\text { Resección en cuña + herniectomía } \\
\text { Ferguson }\end{array}$ & Alarcón y cols. (1) \\
\hline 2009 & 75 años & Gastroenteritis Aguda & Resección de segmento ileal & Jacob y cols. (2) \\
\hline 2010 & 75 años & Hernia inguinoescrotal & Resección en cuña y cols. (3) \\
\hline 2010 & 23 años & Hernia inguinal & Resección en cuña & Yamanaka y cols. (12) \\
\hline 2012 & 74 años & Hernia inguinal & Sección en forma de "V" & Aláez y cols. (5) \\
\hline 2013 & 71 años & $\begin{array}{c}\text { Hernia femoral+ apéndice } \\
\text { gangrenosa }\end{array}$ & $\begin{array}{c}\text { Resección de segmento ileal } \\
\text { tanastomosis termino-terminal }\end{array}$ & Racy y col. (14) \\
\hline
\end{tabular}


No se ha descrito aún el primer caso estudiado por imágenes de forma preoperatoria de la hernia de Littré incarcelada en adultos. Sin embargo, se han descrito algunas técnicas imageneológicas que describen algunos hallazgos que podrían presentarse en esta patología. La TC se ha considerado una prueba de imagen de elección para el diagnóstico del divertículo de Meckel pero con una menor sensibilidad y especificidad para la Hernia de Littré. Otras ayudas diagnósticas son inespecíficas para la hernia de Littré, como el caso de la radiografía de abdomen simple, en donde se evidencia un cuadro de obstrucción intestinal $(2,3,15,17,18)$.

Se concluye entonces que el diagnóstico de la hernia de Littré sólo se establece cuando se produce una complicación del divertículo presente en su interior o en forma incidental cuando se encuentra durante una laparotomía realizada por otra indicación. Los estudios por imágenes preoperatorios no son métodos diagnósticos que permitirán identificar el divertículo presente en el saco herniario (17).

El tratamiento siempre es quirúrgico. La resección quirúrgica de la hernia de Littré y del divertículo de Meckel puede realizarse de manera abierta o por vía laparoscópica. Puede ser programada, incidental o de urgencia $(1,2,17)$.

El procedimiento de elección es la resección intestinal del segmento en donde se encuentra el divertículo y la anastomosis intestinal término terminal, permitiendo una resección de los posibles focos de tejido gástrico que puedan quedar en la base del divertículo. Esta técnica se reserva cuando se tienen las siguientes características: divertículos de base ancha y larga que tengan compromiso de la base, ya sea por perforación o necrosis, y en niños por la controversia del sangrado. Es decir, se debe adaptar en función de las complicaciones y los hallazgos intraoperatorios. En el caso de nuestro paciente, el anterior abordaje descrito fue el utilizado, puesto que era una hernia que presentaba un divertículo de base ancha con signos de perforación $(2,3,18,19)$.

Mediante laparoscopia, con un abordaje transabdominal (TAPP), es factible realizar la disección y resección del divertículo de Meckel y proseguir con la reparación. Se acepta además la diverticulectomía simple con liberación de adherencias. Sin embargo, en la actualidad, el tratamiento más aceptado es la resección intestinal del segmento que contiene el divertículo de Meckel, pues de esta manera se asegura que en el caso de que exista mucosa gástrica ectópica, su resección sea completa $(6,9,10)$.

\section{Conclusión}

El divertículo de Meckel es una entidad poco frecuente con una baja incidencia a nivel mundial (cercana al 2\%), siendo aún más desconocida la incidencia de la Hernia de Littré. Esta última entidad al igual que cualquier hernia estrangulada, representa un importante diagnóstico diferencial en un cuadro de dolor abdominal agudo, si se tienen en cuenta las graves complicaciones sistémicas que podrían llegar a presentarse. De ahí que el cirujano deba pensar en esta patología cuando se enfrente a un paciente con la sintomatología descrita, acompañada de la presencia de una masa inguinal y dolor de rápida evolución sin importar la edad de presentación. Es importante recordar que no existe ningún método paraclínico preoperatorio que permita su diagnóstico, ya que el mismo se hará de manera intraoperatoria al igual que su tratamiento definitivo.

\section{Conflicto de intereses}

Se declara que no existen conflicto de intereses

\section{Referencias}

1. Alarcón J. Hernia de Littré. Colombia Médica. 2005; 36(4):263-265.

2. Jacob T, Gaikwad P, Tirkey A, Raj J. Perforated obturator Littre hernia. Canadian Medical Association. 2009; 52(3): 77-78.

3. Biel A, Vilallonga R, López I, Rodríguez N, Armengo M. Hernia de Littré: Hallazgo inusitado en la reparación de una hernia inguino-escrotal. Revista Española de Enfermedades Digestivas. 2010; 102(8):506-507.

4. Valente E, Goldenberg A, Matos D. Hérnia de Littré. Revista Colombiana Bras. Cir. 2004; 31(1):73-74.

5. Aláez A, Pérez C, Rodríguez G. Hernia de Littré, una causa poco frecuente de obstrucción intestinal. Cirugía y Cirujanos. 2012; 80:186-188.

6. Motta GA, Reyes E, Campos J, García A, Rivera VM, García JA, et al. El divertículo de Meckel en adultos. Anales de Radiología México. 2015; 14:20-30.

7. Pérez JE, Fernández J, Vázquez J, Civera FJ, Mansilla D, Guirao J, et al. Divertículo de Meckel como causa de hemorragia digestiva baja en el adulto. Rev Esp Enferm Dig. 2008; 100(9):592-601.

9. Álvarez RM, Vargas MP, Bulnes D, Gutiérrez P, Tuyub W. 
Divertículo de Meckel asociado a divertículo ileal en un niño. Bol Med Hosp Infant Mex. 2004; 61(1):60-67. 8. Gaspar A, Ramírez M, Rodríguez C, Ramírez J. Diverticulitis de meckel. Acta Médica Grupo Ángeles. 2010; 8(2):20-30.

10. Barrera LM, Vélez JC, Londoño E, López R. Divertículo de Meckel en el paciente adulto. Experiencia en la Fundación Santa Fe de Bogotá. Rev Col Gastroenterol. 2005; 20(3):11-17.

11. Pozo C, Enriquez M, Prats R, Domínguez C. Hernia de Littré. Reporte de un caso. Rev Chil Cir. 2007; 59(4):302304.

12. Yamanaka W, Ortellado F, Gauto r. Hernia de Littre: Reporte de un caso. An Fac Cienc Méd. 2010; 43(2): 61-66.

13. Naranjo M. Diverticulo de merckel. Rev Med Cos Cen. 2012 Dic;69(604): 10-12.

14. Racy M, Ramesh S. Littré meets de Garengeot: Meckel's diverticulum and appendix in a femoral hernia. Ann R Coll Surg Engl. 2013; 95(6):97-98.
15. Brañez C, Vargas B, Vargas J. Divertículo de Meckel Perforado en Paciente en un Paciente de 13 Años, Reporte de un Caso. Gac Med Bol. 2011; 34(1): 40-42.

16. Dicksteina L, Yungb J, Seifarthc F. Inguinal herniation of vitelline duct remnant. 2013; 11(1): 410-412.

17. Kotha V, Khandelwal A, Saboo S, Shanbhogue A, Virmani $\mathrm{V}$, Marginean A, et al. Radiologist's perspective for the Meckel's diverticulum and its complications. Br J Radiol. 2014; 87(1037):20130743.

18. Charles E. Davis Jr. Littre's Hernia: Report of Two Case. Ann Surg. 1954; 139(3): 370-373.

19. Parra R, Parra D, García C, Rojas R. Diagnóstico por imágenes de diverticulitis de meckel: presentación de un caso clínico y revisión de la literatura. Rev chil Radiol. 2003; 9(1): 10-12. 